\title{
Research on the Influence of Internet Finance on the Allocation of Household Assets in the New Middle Class: Setting Shandong Province as an Example
}

\author{
Yingying Sun", Zhi Chen \\ Department of Accounting, Shandong Technology and Business University, Yantai,China
}

Email address:

1840602643@qq.com (Yingying Sun), chenzhi0925@163.com (Zhi Chen)

${ }^{*}$ Corresponding author

\section{To cite this article:}

Yingying Sun, Zhi Chen. Research on the Influence of Internet Finance on the Allocation of Household Assets in the New Middle Class: Setting Shandong Province as an Example. Science Innovation. Vol. 8, No. 6, 2020, pp. 170-175. doi: 10.11648/j.si.20200806.13

Received: November 23, 2020; Accepted: January 8, 2021; Published: January 18, 2021

\begin{abstract}
In the last few years, China's Internet finance has been extremely hot, and Internet financial products develop rapidly. Duo to having the advantages of high profitability, low threshold, various types, convenience and fast transaction, Internet financial products is favored by more families. Especially for the new middle class who have high education and high income, they are more likely to accept Internet financial products. Therefore, Internet finance may have a significant impact on the change of asset allocation structure of the new middle class households. So this paper is based on the Allocation of Household Assets questionnaire data of the new middle class in Shandong Province, analyzed the difference in assets structure between the new middle family of considering Internet financial investment and no consider the Internet financial investment. It is concluded that believes that Internet finance can increase the degree of diversification of the new middle class family assets, encourage households to take part in the financial market, and promote the proportion of investment in risky financial assets. Finally, this paper proposes to some policy suggestions that strengthening the publicity of Internet finance, continuing to encourage the innovation of financial products, and preventing risks of Internet finance, which is to promote the healthy and stable development of Internet finance in China.
\end{abstract}

Keywords: Internet Finance, The New Middle Class, Household Financial Assets Allocation

\section{互联网金融对 “新中产”家庭资产配置影响研究一一以山东省为例}

孙盈盈", 陈智

山东工商学院会计学院, 烟台, 中国

邮箱

1840602643@qq.com（孙盈盈）, chenzhi0925@163.com(陈智）

摘要: 近几年来, 我国互联网金融异常火热, 互联网金融产品爆发式发展。由于互联网金融产品具有高收益、低门槛、 类型繁多、交易方便快捷等优势, 对家庭购买互联网金融产品具有较大吸引力。尤其是具有高学历、高收入的“新中产” 群体, 他们更容易接受互联网金融产品, 对“新中产”家庭资产配置结构变化产生重大影响。因此, 本文基于对山东省 范围内新中产群体展开的调查问卷数据, 分析对比考虑互联网金融投资和不考虑互联网金融投资的新中产家庭结构差 异，得出互联网金融会提高“新中产”家庭资产分散化程度，促进家庭参与金融市场可能性，提高风险性金融资产投资 比例。最后, 本文提出加强互联网金融宣传, 继续鼓励金融工具创新, 防范互联网金融风险等政策建议, 从而促进我 国互联网金融健康稳定发展。 
关键词: 互联网金融, 新中产群体, 家庭资产配置

\section{1. 引言}

随着经济不断发展, 生活水平提高, 一个新的阶层逐渐 显现, 他们就是“新中产阶层”。新中产阶层80后居多, 拥有 较高的学历, 多从事管理类白领工作, 家庭年收入可观, 具 有较强的理财意识。他们是伴随互联网成长起来的年轻群体, 与老中产阶层相比, 在受教育程度、生活消费方式、职业观 念等方面存在很大不同, 这些不同可能导致新老中产阶层家 庭资产配置结构存在很大差异。[1]尤其在互联网金融兴起大 背景下, 出现了具有多样化, 便利化和自由化特点的互联网 金融产品, 为家庭资产配置提供了更多选择机会。[2]新中产 群体具有高学历、高收入, 并对互联网技术具有特殊感情, 所以可能对互联网金融产品接受程度更高, 因此互联网金融 可能会影响“新中产”家庭资产配置。

我国新中产群体已超过 2 亿人, 随着未来经济的发展, 新中产群体规模会越来越庞大, 将在国内社会和经济中占 据不容小㱆的地位。因此，对“新中产”群体购买互联网金 融产品的行为进行研究, 能够更好识别“新中产”家庭资产 配置的特征, 有助于“新中产”家庭资产配置实现利益最大 化, 有助于互联网金融机构了解“新中产”家庭资产配置需 求, 研发出具有针对性的互联网金融产品。而且有助于政 府出台互联网金融相关政策和法规, 促进我国互联网金融 市场的健康稳定发展。

现有有关互联网金融对家庭资产配置的影响文献，主 要从三方面进行理论研究。第一, 互联网金融具有低门槛、 高收益、种类繁多、交易方便快捷等特点, 对居民理财意 识产生了积极影响, 对资产配置结构调整产生了促进作用。 由于互联网金融发展时间较短, 居民对互联网金融保持审 慎态度, 对互联网金融产品的投资比例普遍偏低。（范敏 霞2015)[3]第二是关于互联网金融对家庭资产配置的影响
路径和影响效果分析研究。方文玲（2018）按照互联网金 融业务介绍分析了互联网金融对家庭资产配置的影响路 径。然后基于中国家庭金融数据（CHFS），通过Probit 和Tobit多元线性回归模型, 分析了互联网金融对家庭金融 市场参与可能性、投资占比的影响。[4]李锴（2019）认为 互联网金融培育了我国家庭资产配置意识, 降低了家庭资 产配置门槛, 促进了家庭资产配置行业发展, 对我国家庭 资产配置结构、流动性、风险性、收益性产生了影响。[5] 第三, 关于家庭参与互联网金融投资的影响因素研究。一 些欠发达地区农户因为教育程度低、闲置资金少、家庭结 构等阻碍了其参与互联网金融投资。（何婧2017）[6]综上 可见, 现有文献尚没有深入研究互联网金融对不同社会群 体的家庭资产配置影响差异, 尤其是对互联网金融产品购 买主力军新中产群体, 现在有多少比例的新中产家庭配置 互联网金融产品?对互联网金融产品的投资资金占总资产 的比例是多少? 互联网金融对新中产家庭资产配置影响具 体表现哪些方面？尚没有十分清楚的答案。因此，本文基 于对山东省范围内新中产群体展开的调查问卷数据, 探讨 了互联网金融对新中产的家庭资产配置的影响。

\section{2. 互联网金融的发展}

互联网金融是利用互联网平台, 为客户提供支付、融 资、投资和信息中介服务的一种新型金融业务模式。[7] 北京大学数字金融研究中心将互联网金融划分为六大业 务板块: 互联网支付、互联网信贷、互联网货币基金、互 联网投资理财、互联网保险和互联网征信。[8]

互联网金融对家庭资产配置的影响主要体现在对互 联网金融理财产品的选择上。截至到2019年6月, 我国互 联网理财用户规模达 1.70 亿。如图1所示。

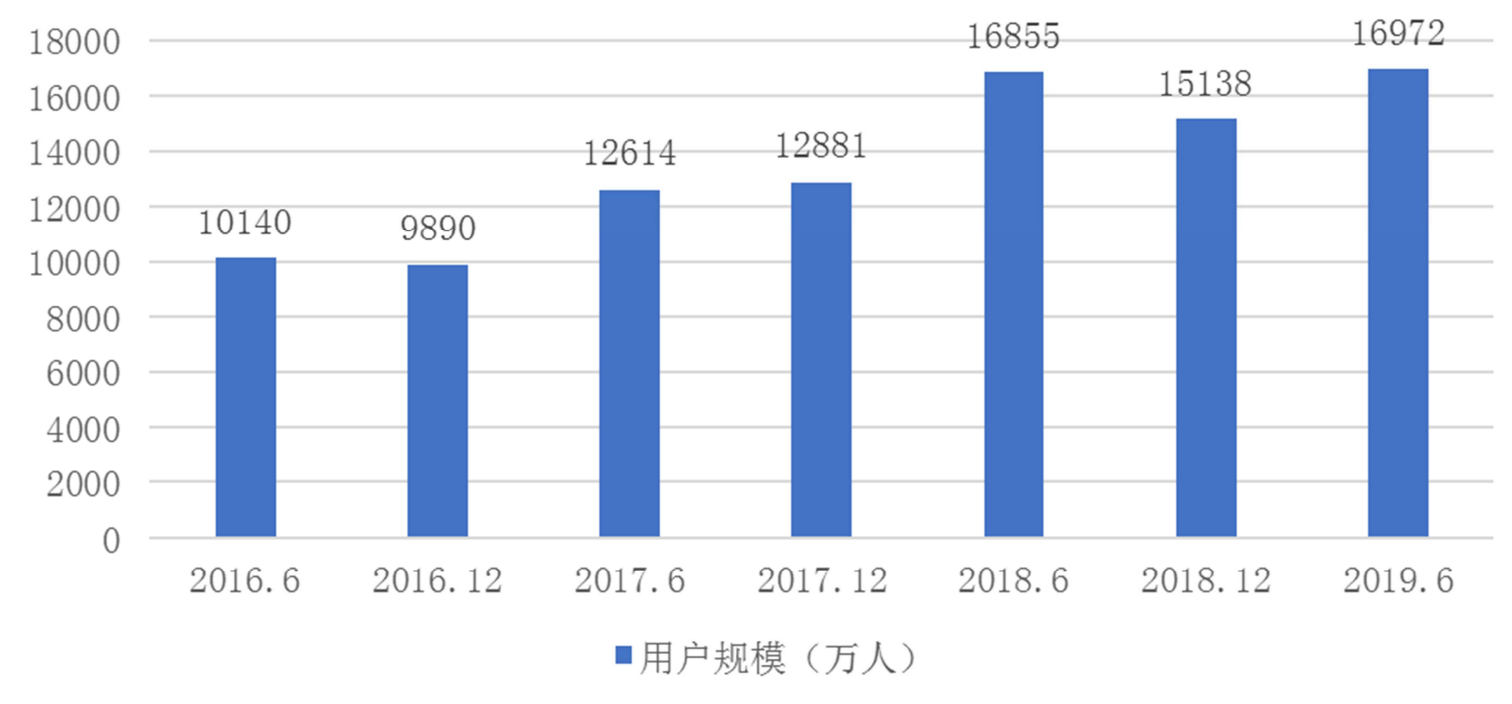

数据来源: 公共资料整理

图1 2016.6-2019.6互联网理财用户规模。 
目前个人家庭主要配置的互联网金融产品有互联网 货币基金、互联网投资理财，比如P2P理财产品、众筹产 品, 互联网保险, 它们给个人家庭和社会发展带来较大影 响。首先, 互联网货币基金产品起购额低、流动性强、收 益率高, 对传统银行存款业务产生巨大冲击。其次, P2P 理财产品是发展最为迅速的一个互联网金融业务板块, 但 是近年来 $\mathrm{P} 2 \mathrm{P}$ 平台暴雷事件频发, 使得投资者们望而却步。 [9]另外, 众筹产品类型很多, 其运营模式获得了众多创业 者和投资人的认可。最后, 互联网保险非常火热, 一些传 统保险产品通过互联网渠道销售, 无中介费用, 无商铺租 金, 极大的满足了卖家与买家的需求。还出现了很多新型 保险产品，深受广大投资者青睐。[10]

不同社会群体对互联网金融产品的参与程度是有差 异的。对于新中产群体来说, 他们是伴随互联网成长起来 的一代年轻人, 具有高学历、高收入特征, 对互联网金融 产品的接受程度更高, 他们将成为购买互联网金融产品主 力军。因此, 对“新中产”配置互联网金融产品的可能性及 配置比例进行研究具有重要意义。

\section{3. 互联网金融下“新中产”家庭资产配置的情况 分析}

改革开放以来山东省经济一直保持稳定增长态势, 从 1998到2018年人均GDP增长了近11倍。居民收入和存款的 大幅度增加逐渐改变了他们的理财观念, 所以对山东省 “新中产”家庭资产配置状况进行分析具有代表意义。[11] 因此，本文通过调查问卷方法了解山东省“新中产”家庭资 产配置状况、互联网金融的参与程度等状况。本问卷包括 三个部分: 第一部分了解受访家庭基本情况; 第二部分考 察受访家庭对互联网金融的参与程度; 第三部分调查受访 家庭资产配置现状。调查对象为山东省“新中产”群体, 即 家庭年收入在 20 万元以上, 拥有本科及其以上学历。通过 “问卷星”在网络上展开随机调查。最后, 篮选剔除不符合 “新中产”标准的问卷。基于有效问卷数据对山东省“新中 产”家庭资产配置现状进行分析研究。

\section{1. “新中产”家庭金融资产和非金融资产持有情况分析}

表1 新中产家庭金融资产和非金融资产持有情况。

\begin{tabular}{llll}
\hline 资产类型 & 资产具体分类 & 资产配置的可能性 & 资产平均配置比例 \\
\hline & 银行活期资金 & $96.72 \%$ & $14.01 \%$ \\
& 银行定期存款 & $78.69 \%$ & $15.07 \%$ \\
& 金融理财产品 & $75.41 \%$ & $12.46 \%$ \\
& 基金产品 & $86.89 \%$ & $15.20 \%$ \\
金融资产 & 保险产品 & $78.69 \%$ & $4.53 \%$ \\
& 股票 & $54.10 \%$ & $6.50 \%$ \\
& 债券 (国债、企业债) & $22.95 \%$ & $1.03 \%$ \\
& 信托 & $3.28 \%$ & $0.47 \%$ \\
& 黄金白银等贵金属 & $36.07 \%$ & $1.70 \%$ \\
& 其他金融产品 & $13.11 \%$ & $1.01 \%$ \\
房产 & $98.36 \%$ & $47.46 \%$ \\
非金融资产 & 耐用消费品 (汽车等) & $100 \%$ & $11.07 \%$ \\
\hline
\end{tabular}

山东省新中产家庭资产分为金融资产和非金融资产 两大类，其中金融资产包括传统型金融资产和互联网金融 资产。从表 1 可以看出, $75 \%$ 以上新中产家庭配置银行存 款、金融理财产品等金融资产，且配置比例占家庭总资产 的 $15 \%$ 左右。 $78.69 \%$ 的新中产家庭配置保险产品, 而配置 比例仅有 $4.53 \%$, 推断出大部分新中产家庭意识到保险产 品是一种防御性资产。超过 $50 \%$ 的新中产家庭持有股票, 但对其配置比例不高, 可看出大多数新中产家庭已经有意 识地配置少量高风险高收益的金融产品。[12]仅有 $20 \%$ 左 右的新中产家庭选择配置债券、信托、黄金、外汇等其他 金融产品, 并且配置比例较低。新中产家庭基本为有车有
房一族，但是房产价值占家庭总资产的一半左右，反映出 大多数新中产家庭资产的流动性较差, 家庭资产配置不合 理。[13]

\section{2. “新中产”家庭持有互联网金融产品情况分析}

目前主要影响家庭资产配置的互联网金融产品包括 互联网货币基金，互联网投资理财，比如P2P理财产品、 众筹产品, 互联网保险。本部分认为调查对象持有以上三 种互联网金融产品之一, 就可称为持有互联网金融投资的 新中产群体。

表2 持有各种互联网金融产品的“新中产”家庭占比。

\begin{tabular}{|c|c|c|c|c|}
\hline \multirow{2}{*}{ 互联网金融产品 } & \multirow{2}{*}{ 互联网货币基金 } & \multicolumn{2}{|c|}{ 互联网投资理财 } & \multirow{2}{*}{ 互联网保险 } \\
\hline & & P2P理财产品 & 众筹产品 & \\
\hline 持有互联网金融产品家庭占比 & $65.57 \%$ & $11.48 \%$ & $4.92 \%$ & $78.69 \%$ \\
\hline
\end{tabular}


表3 持有的各类互联网金融产品占“新中产”家庭资产的比例。

\begin{tabular}{lllll}
\hline \multirow{2}{*}{ 互联网金融产品 } & \multirow{2}{*}{ 互联网货币基金 } & 互联网投资理财 & & \\
\cline { 3 - 5 } & P2P理财产品 & 众筹产品 & \\
\hline 持有互联网金融产品金额占比 & $6.28 \%$ & $0.87 \%$ & $0.35 \%$ & $4.53 \%$ \\
\hline
\end{tabular}

被调查新中产家庭中，持有互联网金融产品的新中产 家庭占有 $96.72 \%$, 可见, 互联网金融已经影响了大多数“新 中产”家庭资产配置结构。[14]表2表明新中产家庭倾向于 配置互联网货币基金产品和互联网保险产品。从表3可以 看出, 新中产家庭购买互联网金融产品资金占总资产的比 例普遍不高, 对受新中产家庭青睐的互联网货币基金产品 的购买资金仅占总资产 $6.28 \%$ 。

\section{3. 互联网金融背景下“新中产”家庭资产配置对比分析}

本部分将持有互联网金融投资和不持有互联网金融 投资品的两组新中产家庭的资产配置进行对比, 分析互联 网金融对“新中产”家庭资产配置结构的影响。[15]

\subsection{1. 互联网金融提高了“新中产”家庭资产分散化程度}

表4 “新中产”家庭持有金融资产种类。

\begin{tabular}{llllll}
\hline 项目 & 三种及三种以下金融资产 & 四种金融资产 & 五种金融资产 & 六种金融资产 & 七种及七种以上金融资产 \\
\hline 持有互联网金融投资 & $7.55 \%$ & $16.98 \%$ & $11.32 \%$ & $18.87 \%$ & $47.17 \%$ \\
不持有互联网金融投资 & $50 \%$ & $37.50 \%$ & $12.50 \%$ & $0 \%$ & $0 \%$ \\
\hline
\end{tabular}

表4数据显示，在持有互联网金融投资的新中产家庭中，47.17\%的新中产家庭持有七种及七种以上金融资产。而 在不持有互联网金融产品的新中产家庭中,一半家庭持有三种及三种以下金融资产, 没有家庭持有超过六种金融资产。 可见，持有互联网金融产品的新中产家庭会配置更多种类金融资产，资产配置分散化程度更高。

\subsection{2. 互联网金融促进了家庭参与传统金融市场可能性}

表5 “新中产”家庭参与传统金融市场可能性。

\begin{tabular}{|c|c|c|c|c|c|c|c|c|c|c|}
\hline 资产项目 & 银行活期 & 银行定期 & 银行理财 & 基金 & 股票 & 债券 & 私募基金 & 信托 & 黄金 & 其他 \\
\hline 持有互联网金融投资 & $96.23 \%$ & $83.02 \%$ & $73.58 \%$ & $75.47 \%$ & $58.49 \%$ & $26.42 \%$ & $11.32 \%$ & $3.77 \%$ & $41.51 \%$ & $15 \%$ \\
\hline 不持有互联网金融投资 & $100 \%$ & $50.00 \%$ & $62.50 \%$ & $37.50 \%$ & $25.00 \%$ & $0 \%$ & $0 \%$ & $0.54 \%$ & $0 \%$ & $9.52 \%$ \\
\hline
\end{tabular}

从表 5 数据可以看出持有互联网金融产品比不持有互联网金融产品的新中产家庭参与传统金融市场的可能性高。这 表明，新中产家庭对互联网金融产品的投资并没有“挤出”家庭对传统金融产品的投资,反而一定程度上会带动家庭参与 传统金融市场。

\subsection{3. 互联网金融提高了风险性金融资产投资比例}

表6“新中产“家庭对传统金融市场投资比例。

\begin{tabular}{|c|c|c|c|c|c|c|c|c|c|c|}
\hline 资产项目 & 银行活期 & 银行定期 & 银行理财 & 基金 & 股票 & 债券 & 私募基金 & 信托 & 黄金 & 其他 \\
\hline 持有互联网金融投资 & $12.27 \%$ & $15.23 \%$ & $9.59 \%$ & $8.73 \%$ & $6.71 \%$ & $1.17 \%$ & $1.47 \%$ & $0.54 \%$ & $1.95 \%$ & $1.39 \%$ \\
\hline 不持有互联网金融投资 & $25.50 \%$ & $14.00 \%$ & $3.75 \%$ & $6.75 \%$ & $5.13 \%$ & $0 \%$ & $0 \%$ & $0 \%$ & $0 \%$ & $0.29 \%$ \\
\hline
\end{tabular}

金融资产分为风险性金融资产 (如股票等) 和无风险 金融资产（如银行活期存款等）。表6报告了两组新中产 家庭资产对传统金融市场投资比例。结果显示，与不持有 互联网金融产品的新中产家庭相比, 持有互联网金融投资 的新中产家庭对传统风险性金融市场投资比例明显较高。

\section{4. 互联网金融背景下影响“新中产》家庭资产配 置的原因分析}

为什么持有互联网金融产品和不持有互联网金融产 品的两组新中产家庭资产配置结构差异会如此之大？本 部分将从三个方面进行原因分析。

\section{1. 金融素养与新中产家庭资产配置}

金融素养在新中产家庭资产配置中扮演重要角色。新 中产群体的金融素养水平参差不齐, 有些新中产群体由于 从事金融相关工作，或者对金融投资比较感兴趣，经常关 注经济和金融知识, 具备较高的金融素养。新中产群体金 融素养水平越高, 越倾向于参与互联网金融市场。[16]而 缺乏金融素养的新中产家庭往往对风险理解不足, 缺失风 险控制能力, 会非理性地远离风险金融市场。所以, 互联 网金融背景下新中产群体的金融素养水平影响了家庭资 产配置情况。 


\section{2. 风险承受能力与新中产家庭资产配置}

两组新中产家庭资产配置结构不同的原因可能是风 险承受能力不同。收入和支出是影响家庭风险承受能力的 主要因素。新中产群体均属于中高等收入水平, 但是每个 家庭的支出情况具有很大差异, 使得家庭风险承受能力不 同。费用支出较大的家庭，更偏好投资低风险金融资产， 甚至无闲置资金配置金融资产。而对于现阶段资金充裕的 新中产群体，他们倾向于尝试投资互联网金融产品和传统 风险性金融产品，实现投资收益最大化。

\section{3. 风险偏好程度与新中产家庭资产配置}

新中产群体风险偏好程度不同导致家庭资产配置结 构存在较大差异。偏好风险的新中产家庭对风险性金融资 产的投资比重远远高于厌恶风险新中产群体; 而风险厌恶 群体比较看重安全、保值的传统金融产品。[17]

\section{5. 政策建议}

为增加新中产家庭考虑互联网金融投资的可能性，促 进互联网金融健康稳定发展, 本部分提出了三条政策建议。

\section{1. 加强互联网金融宣传}

新中产群体学历水平普遍在本科及其以上, 但是一些 新中产群体仍对互联网金融不了解。由此可见, 互联网金 融知识的普及率不高, 加强互联网金融宣传是非常必要的。 首先, 互联网金融行业与传统银行业达成合作, 让传统银 行柜台为投资者推荐介绍互联网金融产品。另外，互联网 金融企业应该加大广告宣传、网络宣传，政府应该出台一 些互联网金融的宣传政策。

\section{2. 鼓励金融工具创新}

新中产家庭购买互联网金融产品的主要原因是其低 门槛、高收益、类型多, 交易方便, 大大提高了家庭资 产配置效率。因此, 继续鼓励金融工具创新, 可以吸引 更多互联网金融投资者。首先，信息科技公司应当加大 顶尖科技的研发，为互联网金融发展提供成熟基础设施。 其次，互联网金融企业应当充分运用高新技术，挖掘客 户潜在理财需求, 设计出具有针对性的互联网金融投资 产品。[18]

\section{3. 防范互联网金融风险}

近几年, 互联网金融暴雷事件频发, 亟需防范互联网 金融安全风险。政府层面, 提高互联网金融机构的准入门 槛, 加强互联网金融机构的日常经营监管, 加重互联网金 融机构违法的惩罚措施。[19]互联网金融机构层面，首先 要自律经营, 在公司内部配置法务部门, 业务宣传要经法 务部门审核批准, 从根本上防范互联网金融风险。还要完 善信息保密和防护技术, 提高互联网金融交易的安全性和 应对信息安全风险的防范能力。家庭层面, 首先保证通过 合规互联网金融平台购买投资理财产品。其次根据自身风
险承受能力和资产总额, 全面估量互联网金融产品的风险 性和收益性。

\section{致谢}

作者感谢本次国际会议所有评审专家的建设性意见 与建议, 感谢老师在写作指导和修改方面给予莫大的帮助, 感谢社会人员配合填写本次问卷调查, 感谢教育部人文社 会科学研究青年基金项目（项目编号:18YJC630196) 和山 东工商学院研究生财富管理专项项目 (项目编号: 2019CF006) 和山东工商学院财务管理特色项目 （2019ZBKY017）资助。

\section{参考文献}

[1] 何神金,朱迪.当代“新中产阶层”研究:概念、发展及趋势[J]. 青年探索,2019(02):68-77。

[2] 蔡宗朝.“互联网+金融”背景下家庭资产配置影响探究[J].金 融经济,2017(08):80-82。

[3] 范敏霞,汤自英,赵梦蕾,周琦轩.互联网金融对居民金融投资 活动的影响[J].西南金融,2015(12):43-48。

[4] 方文玲.互联网金融对家庭资产配置的影响研究[D].集美大 学,2018。

[5] 李锴.互联网金融对我国家庭资产配置影响研究[D].安徽大 学,2019。

[6] 何婧,田雅群,刘甜,李庆海.互联网金融离农户有多远一一欠 发达地区农户互联网金融排斥及影响因素分析[J].财贸经 济,2017,38(11):70-84。

[7] 杨妍炼.互联网金融的发展、风险分析及建议[]].产业创新研 究,2020(10):44-45。

[8] 陈圭栋.互联网金融对居民家庭金融资产配置的影响研究 [D].西安理工大学,2019。

[9] 张婷婷,刘梦琳.互联网金融发展与风险监管探索[J].金融理 论与教学, 2020(02):41-46。

[10] 李洪,孙利君.我国互联网保险发展现状、风险及防范对策[J] 管理现代化,2020,40(02):97-99。

[11] 马玲玲.山东省城镇居民家庭金融资产结构变化研究[D].山 东财经大学,2016。

[12] 吴冠虹,王刚贞,赵培羽,易文静.互联网金融对中国家庭金融 资产配置影响的研究 [J]. 哈尔滨师范大学自然科学学 报, 2018,34(01):33-38。

[13] 陈雨丽. 家庭资产配置现状、问题及对策研究 [J]. 经济 师,2020(03):31-33。

[14] 赵向华.互联网金融对居民金融投资活动的影响[J].中国经 贸导刊(中),2019(11):96-97。 
[15] 魏昭, 宋全云.互联网金融下家庭资产配置 [J]. 财经科 学,2016(07):52-60。

[16] 魏丽萍,陈德棉,谢胜强.互联网金融投资决策:金融素养、风 险容忍和风险感知的共同影响 $[\mathrm{J}]$. 管理 评 论,2018,30(09):61-71。

[17] 宋永辉,邓丽媛.我国家庭金融资产配置影响因素分析[J].沈 阳工业大学学报(社会科学版),2016,9(06):512-518。

[18] 王军强. 当前互联网金融发展现状与展望 [J]. 经济 师,2019(06):57-58。

[19] 侯玉杰.互联网金融发展现状及风险管理研究 [J].现代商 业,2020(12):68-69。

\section{作者简介}

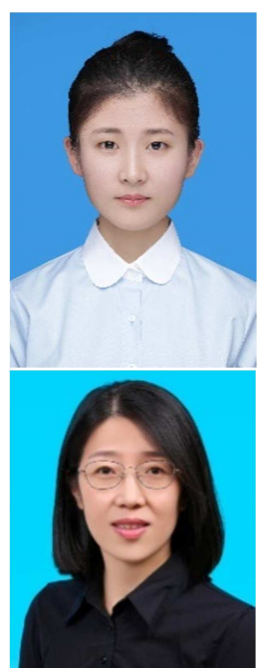

孙盈盈, (1996.10-) 女, 硕士研究生, 研究方向: 审计绩效评价。

陈智, (1978.09-) 女, 副教授, 会计 学博士, 研究方向: 会计信息披露, 绩 效评价。地址: 山东省烟台市莱山区滨 海中路191号。 